\title{
Corrigendum
}

\section{Corrigendum to "Robust Control of Underactuated Systems: Higher Order Integral Sliding Mode Approach”}

\author{
Sami ud Din, ${ }^{1}$ Qudrat Khan, ${ }^{2,3}$ Fazal ur Rehman, ${ }^{1}$ and Rini Akmeliawati ${ }^{2}$ \\ ${ }^{1}$ Department of Electrical Engineering, Capital University of Science and Technology (CUST), Kahuta Road, \\ Express Highway, Islamabad 44000, Pakistan \\ ${ }^{2}$ Department of Mechatronics Engineering, International Islamic University, 50728 Kuala Lumpur, Malaysia \\ ${ }^{3}$ Center for Advanced Studies in Telecommunications, COMSATS Institute of Information Technology, Islamabad 44000, Pakistan \\ Correspondence should be addressed to Sami ud Din; engrsamiuddin@gmail.com
}

Received 25 October 2017; Accepted 26 October 2017; Published 13 November 2017

Copyright (C) 2017 Sami ud Din et al. This is an open access article distributed under the Creative Commons Attribution License, which permits unrestricted use, distribution, and reproduction in any medium, provided the original work is properly cited.

In the article titled "Robust Control of Underactuated Systems: Higher Order Integral Sliding Mode Approach" [1], the affiliation of the first author should be "Department of Electrical Engineering, Capital University of Science and Technology (CUST), Kahuta Road, Express Highway, Islamabad 44000, Pakistan" only. The updated authors' list and affiliations are shown above.

\section{References}

[1] S. ud Din, Q. Khan, F. U. Rehman, and R. Akmeliawati, "Robust Control of Underactuated Systems: Higher Order Integral Sliding Mode Approach," Mathematical Problems in Engineering, vol. 2016, Article ID 5641478, 11 pages, 2016. 


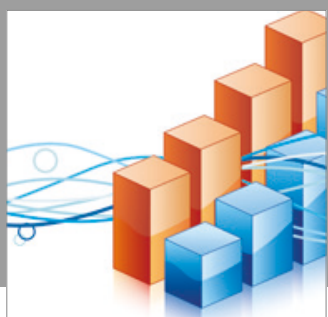

Advances in

Operations Research

vatersals

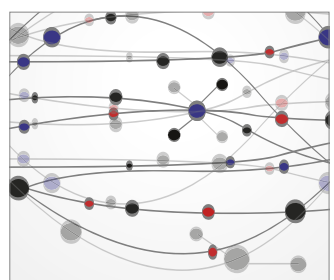

\section{The Scientific} World Journal
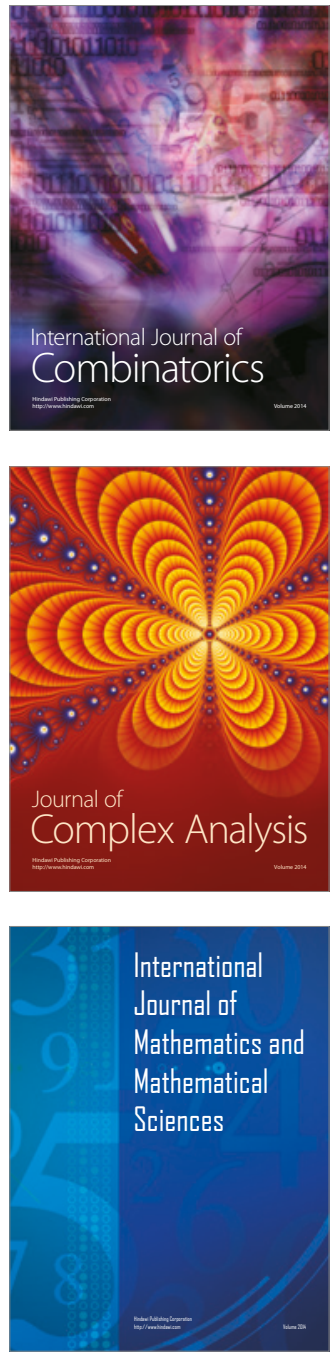
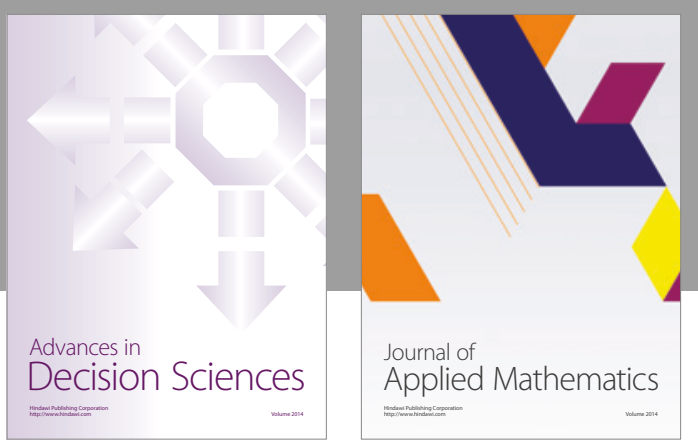

Algebra

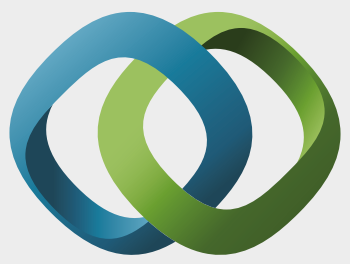

\section{Hindawi}

Submit your manuscripts at

https://www.hindawi.com
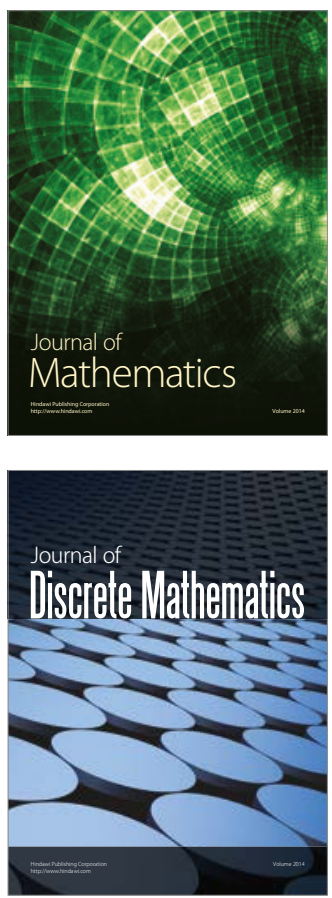

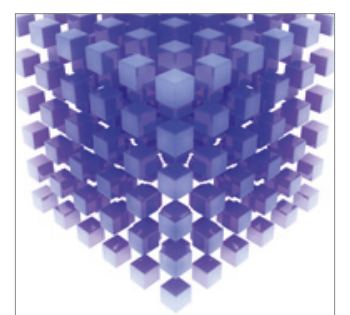

Mathematical Problems in Engineering
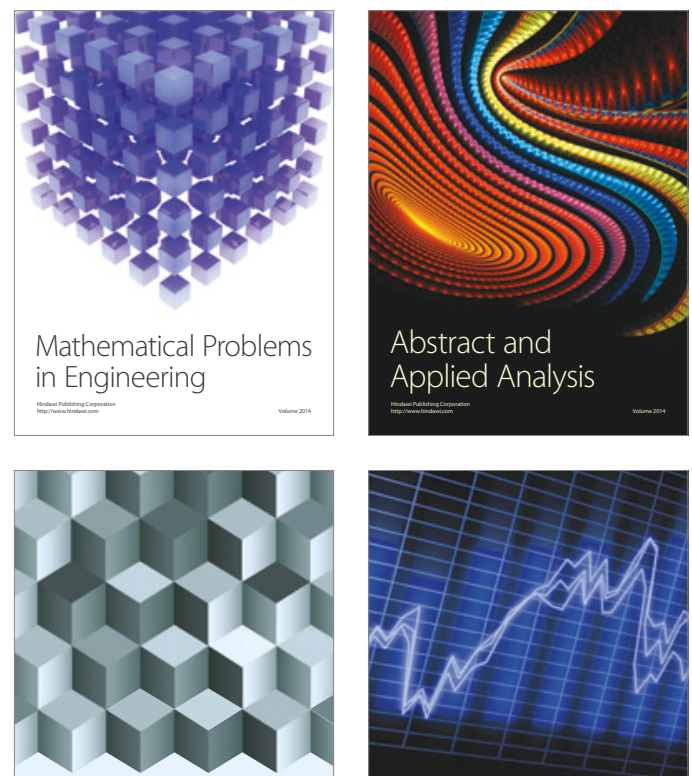

Journal of

Function Spaces

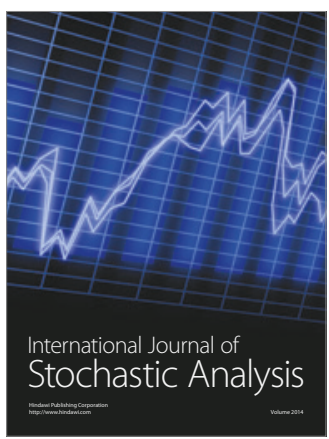

Probability and Statistics
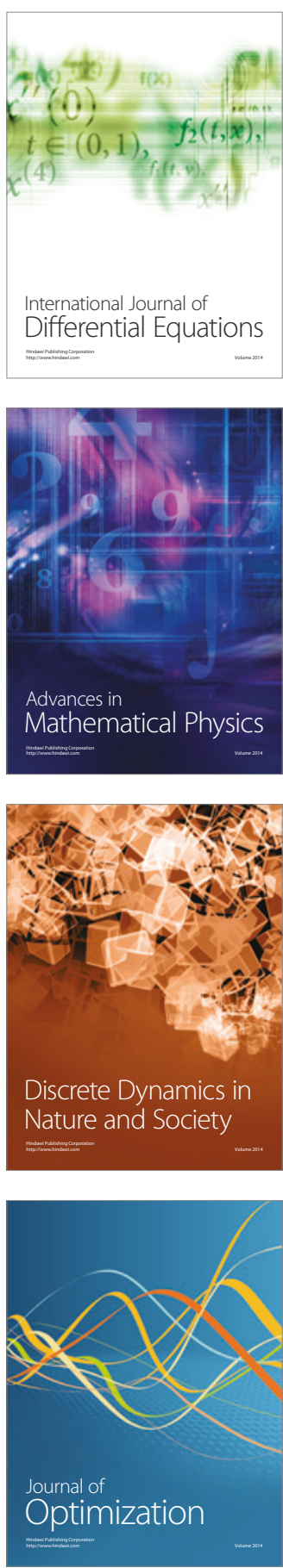